\title{
РОЛЬ И ЗНАЧЕНИЕ МАЛОГО И СРЕДНЕГО ПРЕДПРИНИМАТЕЛЬСТВА В СОВРЕМЕННЫХ УСЛОВИЯХ РАЗВИТИЯ ЭКОНОМИКИ *
}

\author{
(C) 2020 Путихин Ю.Е. \\ кандидат экономических наук, доцент \\ заведующий кафедрой «Экономика и финансы», директор Санкт-Петербургского филиала \\ Финансовый университет при Правительстве Российской Федерации, Россия, Москва \\ E-mail: YEPutihin@fa.ru \\ (C) 2020 Боровицкая М. В. \\ кандидат экономических наук, доцент Департамента бизнес-аналитики \\ Финансовый университет при Правительстве Российской Федерации, Россия, Москва \\ E-mail: MVBorovitskaya@fa.ru \\ (C) 2020 Попова С.C. \\ менеджер Департамента бизнес-аналитики \\ Финансовый университет при Правительстве Российской Федерации, Россия, Москва \\ E-mail: SSPopova@fa.ru
}

Все большее значение в современных условиях развития отечественной экономики имеет развитие малого и среднего предпринимательства. В свете непрекращающихся международных санкций по отношению к России, на первый план выдвигаются задачи импортозамещения, наполнения рынка продовольственных и промышленных товаров продукцией отечественного производства, обеспечение независимости от зарубежных поставщиков. Успешная реализация перечисленных задач невозможна без участия предприятий малого и среднего бизнеса.

Акцент статьи поставлен на раскрытие роли и значения субъектов малого и среднего предпринимательства в современных реалиях функционирования и развития отечественной экономики. В статье обобщены меры причисления к субъектам малого и среднего предпринимательства отвечающие данным от 1 ноября 2019 г., на основе единого реестра субъектов малого и среднего предпринимательства ФНС РФ. Авторами, на основе изучения и анализа статистических источников, средств периодической печати, приведена картина современного состояния и количества предприятий малого и среднего бизнеса, современное состояние и мониторинг количества субъектов по принадлежности к категории малых, средних и микропредприятий, а также оценен их вклад в суммарный оборот экономики РФ.

Авторы отмечают, что несмотря на отставание Российской Федерации от уровня европейских стран по доли субъектов малого предпринимательства, Россия плотно находится в зоне показателей США. В связи с этим необходимо повышение роли государства и разработка необходимых законодательных и нормативных актов в отношении поддержки субъектов малого и среднего предпринимательства. Основополагающим документом, затронутым в статье, является национальный проект РФ «Малое и среднее предпринимательство и поддержка индивидуальной предпринимательской инициативы», ставший по объективным причинам необходимым действенным инструментом поддержки предпринимательства на всех стадиях развития бизнес-процесса: от зарождения предпринимательской идеи до реализации экспортных продаж.

Ключевые слова: малое и среднее предпринимательство, экономические санкции, предпринимательская инициатива, микропредприятие, национальные проекты, стратегические задачи РФ, развитие экономики, импортозамещение.

\footnotetext{
* Статья подготовлена по результатам исследований, выполненных за счет бюджетных средств по государственному заданию Финансового университета
} 
В последние годы на современном этапе развития отечественной экономики, в условиях непрекращающихся международных санкций в отношении России, все большее внимание со стороны правительства уделяется развитию малого и среднего предпринимательства. Реанимируются и создаются новые производственные и сельскохозяйственные экономические единицы малого бизнеса, решающие стратегические и тактические задачи государства в области обеспечения народонаселения страны необходимыми продовольственными и промышленными товарами.

Предприятия малого и среднего бизнеса по мере необходимости и возможности заполняют те ниши экономики, которые вынуждены терпеть лишения в связи с действием международных санкций.

В связи с этим в стране внедрен и успешно действует ряд национальных проектов, касающихся малого и среднего предпринимательства. Важным, насущным и жизненно необходимым проектом является нацпроект «Малое и среднее предпринимательство и поддержка индивидуальной предпринимательской инициативы».

Прежде чем перейти непосредственно к характеристике данного национального проекта остановимся на понятийном аппарате связанным с предпринимательством.

В 2007 г. был принят Федеральный закон от 24 июля 2007 г. № 209-Ф3 «О развитии малого и среднего предпринимательства в Российской Федерации», утвердившего дефиницию «микропредприятие» и «среднее предприятие» и обусловившего критерии отнесения к субъектам малого и среднего предпринимательства [1].

В настоящее время к субъектам МСП в России относятся те предприятия, организации и индивидуальные предприниматели, которые попадают под критерии, закрепленные Федеральным законом от 24 июля 2007 г. № 209-Ф3 «О развитии малого и среднего предпринимательства в Российской Федерации».

Внесенные изменения приблизили российскую практику отнесения фирм к сфере МСП к международной, поскольку за рубежом в среднем верхний порог для средних предприятий составляет около 3 млрд. руб. в пересчете на текущий курс рубля [2].

В отечественной практике к субъектам малого предпринимательства отнесены юридические лица, в форме микропредприятий, малых и средних предприятий, а также индивидуальные предприниматели.

Исключением являются с 2017 г. предприятия легкой промышленности, для которых введены повышенные пороги. Так, например, для данного типа предприятий среднесписочная численность сотрудников может варьировать в пределах от 250 до 1 тыс. человек, что существенно выше установленного общего порога в 250 человек и связано с высокой трудоемкостью обозначенных производств. Действующие на настоящий момент критерии отнесения к субъектам МСП приведены на рисунке 1.

С 1 августа 2016 г. для учета показателей развития сферы МСП был создан Единый реестр субъектов малого и среднего предпринимательства (далее - Единый реестр), оператором которого выступает Федеральная налоговая служба (ФНС). Реестр формируется на основе данных Единого государственного реестра юридических лиц (ЕГРЮЛ) и Единого государственного реестра индивидуальных предпринимателей (ЕГРИП), налоговых деклараций, отчетов о среднесписочной численности и других показателей [3].

Внесение в Единый реестр и приобретение формального статуса субъекта МСП дают организациям и ИП ряд преимуществ, связанных с использованием специальных налоговых режимов, с ведением упрощенного бухгалтерского учета и получением специализированной государственной поддержки и льгот.

По данным Федеральной налоговой службы по состоянию на 10.02.2019 года в РФ в сфере малого и среднего предпринимательства задействовано более $20 \%$ общего числа занятых., а конкретно это 15,8 млн. человек, занятых в деятельности 6 млн. субъектов МСП. Положительная динамика и увеличивающееся число занятых на предприятиях малого и среднего бизнеса свидетельствуют о привлекательности и надежности данного вида бизнеса.

Стоит отметить, что в последнее время число индивидуальных предпринимателей, малых и средних предприятий незначительно сократилась, а вот численность их работников сократилась на 1,9\% (рисунок 2-3, таблица 1).

Свыше 95\% российских МСП - это микробизнес, и более половины этих субъектов действуют в Центральном и Приволжском федеральных округах. Необходима дальнейшая работа со стороны государства в части разра- 
Средняя численность за предшествующий календарный год

Доход от предпринимательской деятельности за предшествующий календарный год

Доля участия в уставном капитале

(независимость происхождения)
• микропредпрития - до 15 человек

- малые предприятия - от 16 до 100 человек

• средние предприятия - от 101 до 250 человек •микропредпрития - 12 млн. руб.

- малые предприятия - 800 млн. руб.

• средние предприятия - 2000 млн. руб.

- Для всех субъектов МСП до 25\% для РФ, субъектов РФ, муниципальных образований, общественных и религиозных организаций (объединений),

благотворительных и иных фондов, за исключением суммарной доли участия, входящей в состав активов инвестиционных фондов.

- До 49\% для иностранных юридических лиц и (или) юридических лиц, не являющихся субъектами малого и среднего предпринимательства.

Рисунок 1. Меры причисления к субъектам малого и среднего предпринимательства (по состоянию на 1 ноября 2019 г.)

Количество субъектов МСП

Чнленность работников
• на 10.02.2019 - 6,1 млн.ед

• на 10.02.2018 - 6,1 млн.ед •на 10.02.2019 - 15,8 млн. ел.

• на 10.02.2018 - 16,1 млн. чел.

\section{Рисунок 2. Численность субъектов МСП в России}

Оборот малых компаний, включая микропредприятия

\section{Оборот средних компаний}

• 2016 г. - 38,9

•2017 г. - 48,5

•2016 г. $-6,7$

•2017 г. - 6,3

Рисунок 3. Оборот субъектов МСП в 2016-2017 годах, трлн. руб. 
Таблица 1. Динамика соотношения численности субъектов по принадлежности к категории

\begin{tabular}{|c|c|c|c|c|c|c|c|c|}
\hline \multirow[b]{2}{*}{$\begin{array}{l}\text { № } \\
\text { п.П. }\end{array}$} & \multirow[b]{2}{*}{ Год } & \multirow[b]{2}{*}{$\begin{array}{c}\text { Всего МСП } \\
\text { в РФ, ед. }\end{array}$} & \multicolumn{2}{|c|}{ Микро } & \multicolumn{2}{|c|}{ Малые } & \multicolumn{2}{|c|}{ Средние } \\
\hline & & & Всего, ед. & $\begin{array}{c}\text { Доля от об- } \\
\text { щего числа } \\
\text { МСП, \% }\end{array}$ & Всего, ед. & $\begin{array}{c}\text { Доля от об- } \\
\text { щего числа } \\
\text { МСП, \% }\end{array}$ & Всего, ед. & $\begin{array}{c}\text { Доля от об- } \\
\text { щего числа } \\
\text { МСП, \% }\end{array}$ \\
\hline 1 & 2016 & 5841509 & 5551944 & 95,04 & 268901 & 4,60 & 20664 & 0,35 \\
\hline 2 & 2017 & 5998371 & 5710383 & 95,20 & 267630 & 4,46 & 20358 & 0,34 \\
\hline 3 & 2018 & 6042898 & 5772301 & 95,52 & 251730 & 4,17 & 18867 & 0,31 \\
\hline 4 & на 10.11.19 & 5893148 & 5650666 & 95,89 & 225396 & 3,82 & 17086 & 0,29 \\
\hline
\end{tabular}

ботки и принятия нормативных актов, смягчающих налоговое бремя предприятиям малого и среднего бизнеса, а также расширение государственной поддержки малому и среднему предпринимательству. Это в значительной мере будет способствовать расширению МСП и в других регионах страны.

За 2017 год оборот МСП, принадлежащих к микро-, был 48,5 трлн. руб. Выручка средних предприятий по данным Росстата - 6,3 трлн. руб. (рисунок 3).

Оборот увеличился довольно ощутимо, порядка 25\%. По сравнению с ростом совокупной выручки отечественных предприятий, который вырос на 6\% относительно прошлого года, данный показатель ощутимо вырос. Благодаря этому факту, в 2017 г. доля малого предпринимательства в совокупном обороте российских предприятий достигла 30,5\%, показав рост более чем на 4 пункта. Тем самым, по данным Минэкономразвития России, вклад малого предпринимательства во внутренний валовый продукт составил порядка 19,9\%. Данные циф- ры свидетельствуют о положительной динамике в области развития малого и среднего предпринимательства, что не может не радовать. Но останавливаться на достигнутом и пожинать лавры еще преждевременно. Это только начало грандиозной и очень важной работе в области развития малого бизнеса.

Ключевые задачи национального проекта РФ определяющего развитие предпринимательства в нашей стране представлены на рисунке 4:

Следует отметить и такие задачи данного проекта, как формирование инфраструктуры и сервисов поддержки всех субъектов МСП, привлечение субъектов малого бизнеса в такие отрасли как научно-техническая и социальная сферы, экология и благоустройство городской среды. Очень важно привлечь внимание предпринимателей к сельскому хозяйству, сформировать систему поддержки фермерских хозяйств, в целях расширения и развития сельской кооперации.

Совокупные расходы на национальный проект РФ «Малое и среднее предпринимательство
Обеспечение благоприятных условий осуществления деятельности самозанятыми гражданами посредством создания нового режима налогообложения

Совершенствование нормативно-правового регулирования системы закупок
Повышение доступности инструментов лизинга для субъектов МСП

Повышение доступности финансирования микро- и малого бизнеса за счёт микрофинансовых организаций (МФО) и краудфандинга.
Улучшение условий
ведения

предпринимательской деятельности

Создание цифровой платформы, ориентированной на информационную поддержку

производственной и сбытовой деятельности субъектов МСП
Упрощение доступа к льготному финансированию
Развитие инструментов фондового рынка 
и поддержка индивидуальной предпринимательской инициативы» до 31.12.2024 года составят 481,8 млрд. рублей, в том числе как показано на рисунке 5 [5]:

Срок реализации нацпроекта 2019-2024 года.

Проект выполняется в рамках второй подпрограммы «Развитие малого и среднего предпринимательства» государственной программы «Экономическое развитие и инновационная экономика».

Национальный проект призван осуществить меры поддержки предпринимательства на всех стадиях развития бизнес-процесса: от зарождения предпринимательской идеи до реализации экспортных продаж.

Успешное воплощение в жизнь названных проектов в области малого и среднего бизнеса, а также всесторонняя разумная поддержка их со стороны государства, позволит значительно поднять уровень развития отечественной экономики, тем самым свести к минимуму импортозависимость значительного числа ее отраслей.

В 2019 году произошло немало знаменательных событий в сфере малого и среднего бизнеса, но создается впечатление, что принятый закон «О развитии малого и среднего предпринимательства в Российской Федерации», а также национальный проект «Малое и среднее предпринимательство и поддержка индивидуальной предпринимательской инициативы», в большей степени рассчитаны на перспективу, а не на сегодняшний день.

Данные проведенного масштабного опроса субъектов малого бизнеса касательно того, как реализуется нацпроект «Малое и среднее предпринимательство и поддержка индивидуальной предпринимательской инициативы», при участии порядка 83 тысяч представителей малых предприятий 83 регионов страны, указали на то, что более половины представителей вообще не имеют представление о целях проекта, а 50\% уверены в том, что условия, созданные для представителей малого бизнеса в стране стали не изменились к лучшему.

По данным опроса было выявлено пять ключевых проблем, волнующих представителей малого и среднего бизнеса, и не учтенных в рамках проекта (рисунок 6).

Предприниматели ждут включения указанных проблем в национальный проект и надеются на взаимопонимание со стороны руководства страны.

Ситуация, сложившаяся с малым и средним бизнесом в России к 2020 году, в связи с объективными и субъективными причинами весьма сложная и противоречивая. Это характеризуется и снижением числа субъектов малого предпринимательства и особенно среднего, и государству не удается предотвратить данный процесс. Несмотря на это работа в данном направлении

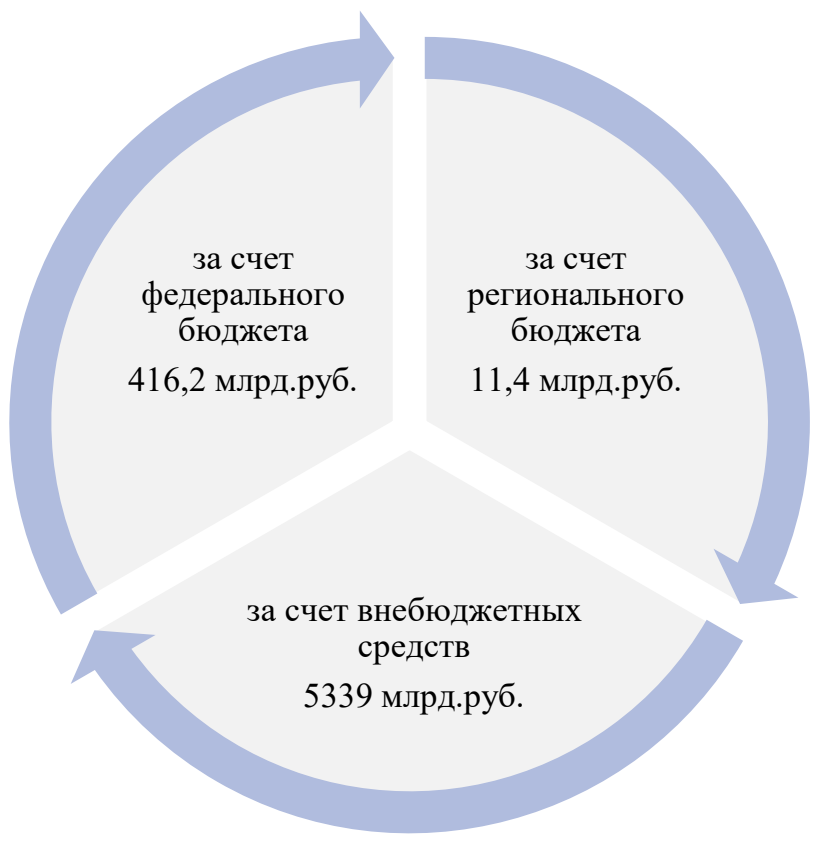

Рисунок 5. Совокупные расходы на национальный проект РФ «Малое и среднее предпринимательство и поддержка индивидуальной предпринимательской инициативы» 
Таблица 2. Численность юридических лиц и индивидуальных предпринимателей в Российской Федерации на 10.02.2019 года, тыс. единиц

\begin{tabular}{|c|c|c|c|c|c|c|c|c|c|}
\hline \multirow{4}{*}{ Субъект РФ } & \multirow{4}{*}{ Всего } & \multicolumn{8}{|c|}{ из них } \\
\hline & & \multicolumn{4}{|c|}{ Юридических лиц } & \multicolumn{4}{|c|}{ Индивидуальных предпринимателей } \\
\hline & & \multirow{2}{*}{ всего } & \multicolumn{3}{|c|}{ из них } & \multirow{2}{*}{ всего } & \multicolumn{3}{|c|}{ Из них } \\
\hline & & & микро & малых & средних & & микро & малых & средних \\
\hline $\begin{array}{l}\text { Российская Федера- } \\
\text { ция в целом }\end{array}$ & 6058,3 & 2724,3 & 2483,1 & 222,8 & 18,5 & 3334,0 & 3306,4 & 27,3 & 0,3 \\
\hline $\begin{array}{l}\text { Центральный феде- } \\
\text { ральный округ }\end{array}$ & 1875,6 & 962,6 & 874,5 & 80,8 & 7,3 & 913,0 & 906,6 & 6,2 & 0,1 \\
\hline $\begin{array}{l}\text { Северо-Западный } \\
\text { федеральный округ }\end{array}$ & 710,4 & 378,1 & 347,0 & 28,9 & 2,2 & 332,3 & 329,9 & 2,4 & 0,0 \\
\hline $\begin{array}{l}\text { Южный федераль- } \\
\text { ный округ }\end{array}$ & 709,3 & 207,3 & 188,7 & 17,2 & 1,4 & 502,1 & 498,5 & 3,5 & 0,0 \\
\hline $\begin{array}{l}\text { Северо-Кавказский } \\
\text { федеральный округ }\end{array}$ & 201,3 & 48,6 & 43,8 & 4,3 & 0,4 & 152,7 & 151,9 & 0,8 & 0,0 \\
\hline $\begin{array}{l}\text { Приволжский феде- } \\
\text { ральный округ }\end{array}$ & 1082,6 & 471,5 & 427,3 & 41,0 & 3,2 & 611,1 & 604,7 & 6,3 & 0,1 \\
\hline $\begin{array}{l}\text { Уральский феде- } \\
\text { ральный округ }\end{array}$ & 519,5 & 233,2 & 213,7 & 18,1 & 1,4 & 286,3 & 283,6 & 2,7 & 0,0 \\
\hline $\begin{array}{l}\text { Сибирский феде- } \\
\text { ральный округ }\end{array}$ & 644,4 & 294,9 & 270,7 & 22,4 & 1,7 & 349,5 & 346,2 & 3,3 & 0,0 \\
\hline $\begin{array}{l}\text { Дальневосточный } \\
\text { федеральный округ }\end{array}$ & 315,2 & 128,2 & 117,4 & 10,1 & 0,7 & 187,1 & 185,0 & 2,1 & 0,0 \\
\hline
\end{tabular}

снижение налоговой нагрузки

защита бизнеса от блакировки счетов уменьшение количества форм и вилов бухгалтерской и налоговой отчетности

снижение чила проверок

\section{Рисунок 6. Проблемы, волнующие МСП, не входящие в задачи национального проекта}

не прекращается, ни со стороны государства, ни со стороны малого и среднего предпринимательства. Положительные тенденции весьма заметны. Так, по мнению мэра Москвы Сергея Собянина, малый и средний бизнес приносит в бюджет города четверть всех налоговых поступлений.

Проект «Популяризация предпринимательства» в настоящее время показал активную популяризацию. С победителями конкурса на реализацию мероприятий в рамках данного проекта, которыми стали Университет «Синергия» и аналитический центр «НАФИ» в 2019 г. были заключены контракты на 798 млн. руб., и
27 млн. руб. соответственно. Президентом России был подписан закон, распространяющий меры поддержки субъектов малого и среднего предпринимательства (МСП) на самозанятых граждан, участвующих в процедуре закупок госкомпаний. Представители малого и среднего бизнеса теперь имеют возможность сообщить о нарушениях, допущенных во время камеральных проверок на портале бизнес-навигатора Корпорации МСП.

Резюмируем все вышесказанное словами министра экономического развития Максима Орешкина - «малый бизнес должен стать движущей силой развития экономики». 


\section{Библиографический список}

1. Федеральный закон «О развитии малого и среднего предпринимательства в Российской Федерации» от 24.07.2007 N 209-ФЗ.

2. Ткачев А.А., Решетникова Е. Е. Аудит эффективности в системе государственного финансового контроля//В сборнике: Математические методы и модели в управлении, экономике и социологии сборник научных трудов. Тюмень, 2017. С. 358-361.

3. Бюллетень Счетной палаты № 10 (октябрь) 2019 г.- Отчет о результатах контрольного мероприятия «Проверка эффективности и результативности мер финансовой поддержки малого и среднего предпринимательства в Дальневосточном федеральном округе в 2015-2018 годах». [Электронный ресурс] - Режим доступа: http://www.ach.gov.ru/statements/byulleten-schetnoj-palaty-10-oct-2019

4. Указ Президента РФ от 07.05.2018 N 204 (ред. от 19.07.2018) «О национальных целях и стратегических задачах развития Российской Федерации на период до 2024 года».

5. «Паспорт национального проекта «Малое и среднее предпринимательство и поддержка индивидуальной предпринимательской инициативы» (утв. президиумом Совета при Президенте РФ по стратегическому развитию и национальным проектам, протокол от $24.12 .2018 \mathrm{~N} 16)$.

6. Петров А.М. «КОНТРОЛЬ ЗА ДВИЖЕНИЕМ ДЕБИТОРСКОЙ И КРЕДИТОРСКОЙ ЗАДОЛЖЕННОСТИ» Современный бухучет. 2004. № 9. С. 38.

7. Карпова Т.П., Петров А.М., Горбаткова Г.А., Самарина Л.Б., ДашкинаГ.Г., Сидорова М.И., Сабанин Р.Л., Ситникова В. А., Листопад Е. Е. «БУХГАЛТЕРСКИЙ УЧЕТ В СФЕРЕ УСЛУГ» Учебник для студентов высшего профессионального образования, обучающихся по специальности 080109 «Бухгалтерский учет, анализ и аудит» / Под редакцией М.А. Вахрушиной; Министерство образования и науки Российской Федерации, Федеральное государственное учреждение «Федеральный институт развития образования». Москва, 2011. Сер. Читай

8. Петров А.М., МеЛьниковаЛ.А. «ФОРМИРОВАНИЕ ОТЧЕТНОСТИ В СООТВЕТСТВИИ С ТРЕБОВАНИЯМИ МСФО КАК ОБЪЕКТИВНАЯ НЕОБХОДИМОСТЬ НА СОВРЕМЕННОМ ЭТАПЕ РАЗВИТИЯ ЭКОНОМИКИ РФ» Проблемы современной экономики. 2017. № 2 (62). С. 105-107.

9. Петров А.М., КоняхИн А. Н. «УЧЕТНАЯ ПОЛИТИКА ПРИ ПОДГОТОВКЕ ПЕРВОЙ ОТЧЕТНОСТИ СОГЛАСНО МСФО» Международный бухгалтерский учет. 2013. № 11 (257). С. 2-15.

10. Петров А.М., ЛЫмарь М. П. «СОСТАВ БУХГАЛТЕРСКОЙ ОТЧЕТНОСТИ В РОССИИ И КИТАЕ» МеЖДУНароднЫЙ бухгалтерский учет. 2014. № 31 (325). С. 28-37.

11. Петров А.М., ЛЫМарь М.П. «СРАВНИТЕЛЬНАЯ ХАРАКТЕРИСТИКА ОСНОВНЫХ ПОЛОЖЕНИЙ ЗАКОНОВ, РЕГУЛИРУЮЩИХ БУХГАЛТЕРСКИЙ УЧЕТ В КИТАЕ И РОССИИ» МежДУНародНЫЙ бухгалтерскиЙ учет. 2013. № 40 (286). С. 52-60.

12. Петров А.М., ЛЫмарь М.П. «СРАВНИТЕЛЬНЫЙ АНАЛИЗ БУХГАЛТЕРСКОГО УЧЕТА АКТИВОВ В РОССИИ И КИТАЕ» Международный бухгалтерский учет. 2014. № 27 (321). С. 34-48. 